ACADEMIA ROMÂNĂ Roum. Chim.,
Revue Roumaine de Chimie
http://web.icf.ro/rrch/

\title{
PROGRESS IN PHOTOCATALYSIS OF NEW TWO-DIMENSIONAL LAYERED MATERIALS MXENES
}

\author{
Chunmei KAI, ${ }^{a}$ Fengjun ZHANG, ${ }^{\text {a,b, }}{ }^{*}$ Cui $\mathrm{KONG}^{\mathrm{a}}$ and Weiqin $\mathrm{CAI}^{\mathrm{a}}$ \\ ${ }^{a}$ Key Laboratory of Functional Molecule Design and Interface Process, Anhui Jianzhu University, Hefei Anhui, 230601, P. R. China \\ ${ }^{\mathrm{b}}$ Anhui Key Laboratory of Advanced Building Materials, Anhui Jianzhu University, Hefei Anhui, 230022, P. R. China
}

Received September 6, 2020

As an extremely promising new class of materials, MXenes (twodimensional layered materials) have attracted much interest and become a research hotspot in many fields. Owing to the typical layered structure, excellent electronic performance, it can be used as co-catalysts to recombine other photocatalytic materials to enhance the separation of photo-generated charges, inhibit the rapid recombination of charges, and finally convert solar energy into chemical energy. MXenes, which exhibit extraordinary catalytic activity in photocatalytic reactions, are increasingly being widely used as co-catalysts. This article summarizes and discusses two photocatalytic reactions with MXenes as co-catalysts, the dehydrogenation reaction (HER) and the $\mathrm{CO}_{2}$ reduction reaction $\left(\mathrm{CO}_{2} \mathrm{RR}\right)$, as well as their physical and chemical properties, preparation and synthesis methods, and the latest research progress. Summarized related applications and photocatalysis principles. Finally, the prospects and expectations of MXenes in photocatalytic applications are presented.

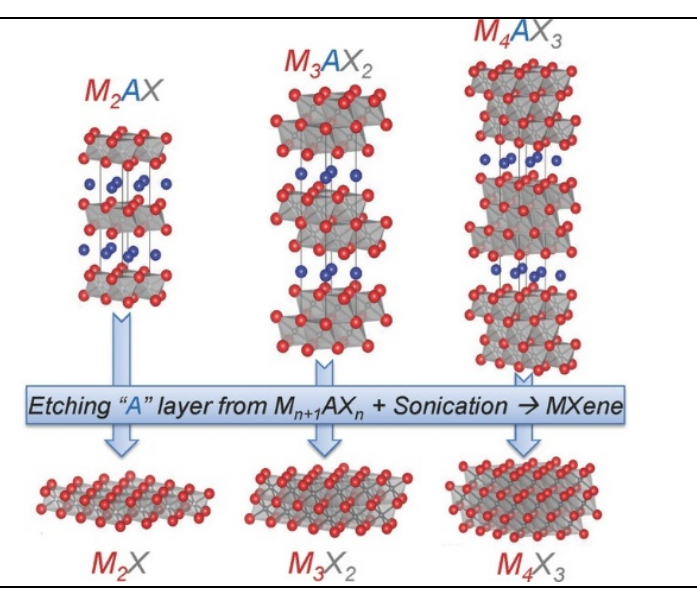

\section{INTRODUCTION}

Nowadays, resource shortage has become the biggest problem facing human beings. Developing clean energy to replace traditional fossil fuels has become a top priority. ${ }^{1-2}$ Solar energy is an inexhaustible and inexhaustible clean energy. Converting solar energy into chemical energy by using photocatalytic technology is considered as a wise and appropriate choice to solve the global energy shortage. ${ }^{3-6}$ The conversion of solar energy is a complex physical and chemical process that generally involves three links: (I) light energy absorption, (II) photo-generated charge separation and transfer, (III) interface reaction. ${ }^{7}$ It is now generally possible to improve the overall efficiency of photocatalysis by improving these steps. Photocatalysts play a crucial role in photocatalytic hydrolysis of hydrogen production and carbon dioxide reduction. ${ }^{8-10}$ Conventional photocatalysts, such as $\mathrm{TiO}_{2},{ }^{11-15} \mathrm{~g}_{-} \mathrm{C}_{3} \mathrm{~N}_{4}{ }^{16-18}$ and other photocatalysts, exhibit low conversion efficiency due to rapid charge recombination. ${ }^{19-20}$ Therefore, it is necessary to find a co-catalyst to inhibit charge recombination and enhance separation ability.

As a new type of two-dimensional layered materials, MXenes are promising co-catalysts. They are carbide or nitride of the pre-transition metal with the molecular formula $\mathrm{M}_{\mathrm{n}+1} \mathrm{X}_{\mathrm{n}}$, where $\mathrm{M}$ is the pre-transition metal, $\mathrm{X}$ is carbon or nitrogen, $\mathrm{n}=1,2$ or 3 , and its shape is accordionlike. $^{21-22}$ To emphasize its similar structure to

\footnotetext{
* Corresponding author: fjzhang@ahjzu.edu.cn
} 
graphene, it is called MXenes. In 2011, Naguib et al. ${ }^{23}$ used hydrofluoric acid (HF) to selectively etch the $\mathrm{Al}$ metal layer in $\mathrm{Ti}_{3} \mathrm{AlC}_{2}$ and then peel off to obtain two-dimensional layered $\mathrm{Ti}_{3} \mathrm{C}_{2}$, which is also the first report on MXenes. After that, different MXenes systems have been synthesized successively, including $\mathrm{Ti}_{2} \mathrm{C}^{24}{ }^{24} \mathrm{Ta}_{4} \mathrm{C}_{3},{ }^{25} \mathrm{Ti}_{3} \mathrm{CN},{ }^{26}$ $\mathrm{Nb}_{2} \mathrm{C},{ }^{27} \mathrm{Nb}_{4} \mathrm{C}_{3},{ }^{28} \mathrm{Mo}_{2} \mathrm{C},{ }^{29} \mathrm{Mo}_{2} \mathrm{TiC}_{2},{ }^{30} \mathrm{Mo}_{2} \mathrm{Ti}_{2} \mathrm{C}_{3},{ }^{31}$ $\mathrm{Cr}_{2} \mathrm{TiC}_{2}{ }^{32}$ and so on. Due to the reason of synthesis method and super high surface activity, the surface of MXenes synthesized at present is covered by functional groups such as $-\mathrm{O},-\mathrm{OH}$ and $-\mathrm{F}$ (the molecular formula is $M_{n+1} X_{n} T_{X}$, and $T$ is the terminal functional group). It has many superior properties including adjustability of element composition and structure, metal properties, anisotropy of carrier migration, good optical and mechanical properties, etc., so this material is expected to play a key role in the field of photocatalysis. $^{33}$

It is noteworthy that MXenes are a young and large family that can be used in green chemistry fields, such as photocatalytic hydrogen production and carbon dioxide reduction. ${ }^{34}$ Since Naguib et al. reported this new type of two-dimensional transition metal carbide in 2011, it has attracted great attention from the scientific community. To date, there are more than 70 members of the MXenes family. ${ }^{35}$ It uses ternary ceramic phase MAX as precursor and selectively etches A layer by high concentration of hydrofluoric acid to obtain MXene material. ${ }^{36}$ Because MXene materials have many excellent properties, such as its unique anisotropic structure in the plane, good metallicity and hydrophilicity, it has attracted the interest of many researchers in recent years. ${ }^{37,38} \mathrm{In}$ this review, the structure, physical and chemical properties, preparation methods and progress in photocatalytic applications of two-dimensional MXenes will be introduced to further understand and understand MXenes materials.

\section{STRUCTURE AND PROPERTIES OF MXenes}

\section{Structure of MXenes}

MXenes are an emerging 2D material containing transition metal carbides and nitrides exfoliated from MAX phase precursors $\left(M_{n+1} A X_{n}\right)$ $(\mathrm{M}=\mathrm{Mo}, \mathrm{Ti}, \mathrm{Zr}, \mathrm{Cr} ; \mathrm{A}=\mathrm{Al}, \mathrm{Ga}, \mathrm{Ge}, \mathrm{Si} ; \mathrm{X}=\mathrm{C}, \mathrm{N}$; $\mathrm{n}=1-3)$; the structure and composition of MXenes are determined by the crystalline structure of MAX $^{39,40}$ Typically, according to the $n=1-3$ range, the MAX phase is divided into three different types, including 211,312 , and 413 , as shown in the figure. It can be observed that the crystal units are arranged in a hexagonal structure, and the space point group belongs to $\mathrm{P} 63 / \mathrm{mmc}$, in which the Mlayer atoms and A-layer atoms are arranged alternately, while the X-atoms are filled in the void positions of the octahedron; while the MAX phase contains metal bonds, covalent bonds and ionic bonds. ${ }^{41}$ The $\mathrm{M}-\mathrm{X}$ bond is a covalent/metal/ion bond hybrid bond, and the bonds formed by the $\mathrm{A}$ layer atoms are relatively weak and easy to react, so the A layer atoms can be removed to obtain MXenes. As shown in Figure $1,{ }^{21}$ the crystal structure of MXenes is usually hexagonal closepacked (HCP). However, the $\mathrm{M}$ atom in $\mathrm{M}_{2} \mathrm{X}$ shows the $\mathrm{HCP}$ sequence (ABABAB), while $\mathrm{M}_{3} \mathrm{X}_{2}$ and $\mathrm{M}_{4} \mathrm{X}_{3}$ show the face-centered cubic (FCC) sequence $(\mathrm{ABCABC})$.

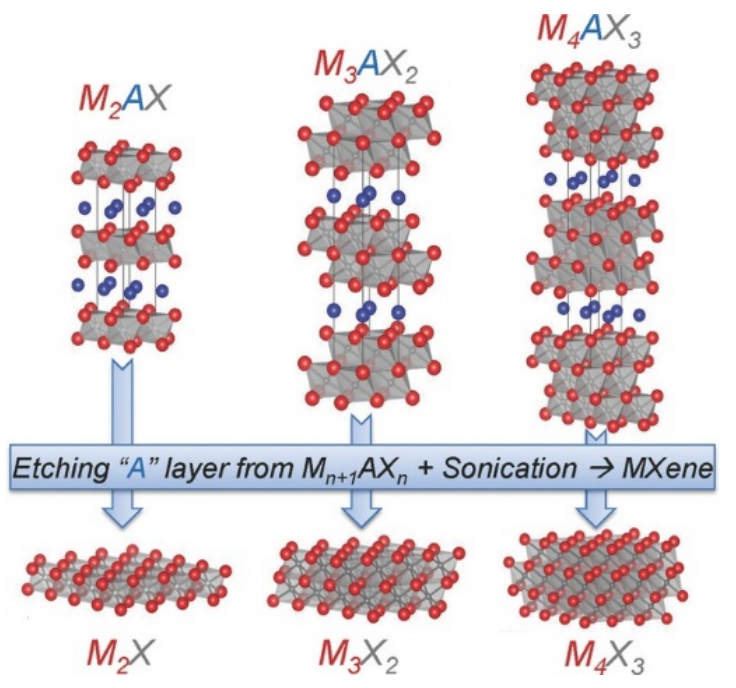

Fig. 1 - Structure diagram of MAX phase and corresponding MXene. ${ }^{21}$

In 2011, Naguib et al. innovatively used a high concentration of hydrofluoric acid (HF) solution to selectively etch $\mathrm{Ti}_{3} \mathrm{AlC}_{2}$ ceramics. Hydrofluoric acid, as an etchant, can selectively etch the Al layer so that the Ti-Al bond is broken without breaking the Ti-C bond, thus forming a two-dimensional $\mathrm{Ti}_{3} \mathrm{C}_{2} \mathrm{~T}_{\mathrm{x}}$ ( $\mathrm{T}$ stands for the surface groups -OH, - $\mathrm{F}$ and $-\mathrm{O}$, etc.). Because MXenes are synthesized by etching with strong acids (e.g., hydrofluoric acid), their surfaces are usually connected with various terminal functional groups (e.g., $\mathrm{OH}, \mathrm{O}$, and $\mathrm{F})$. It is worth noting that the synthesis conditions used determine the distribution of these functional 
groups on their surfaces, such as etchant, $\mathrm{pH}$ and temperature. They used the same experimental method and also successfully prepared more MXenes materials such as $\mathrm{Ti}_{2} \mathrm{C}$ and $\mathrm{Ta}_{4} \mathrm{C}_{3}$. At present, more than 70 kinds of MXenes can be calculated. ${ }^{42}$ Among them, 19 kinds of MXenes materials have been successfully synthesized, and other potential MXenes materials have been predicted by theoretical calculation.

\section{Nature}

\subsection{Stability of MXenes}

The thermal stability of materials is of great significance for practical applications. Materials with stable performance will have a wider application field and a longer life of materials. Enyashin at al. ${ }^{43}$ compared $\mathrm{Ti}_{2} \mathrm{C}$ with $\mathrm{Ti}_{3} \mathrm{C}_{2}$ and the types terminated by $\mathrm{OCH}_{3}$ groups, and found that the stability and lattice parameters mainly depended on the types covered by $\mathrm{OCH}_{3}$. Methoxide coordination with the tetrahedron of $\mathrm{O}$ atom above the vacancy between three adjacent carbon atoms is the most favorable, indicating that the end group has a certain influence on stability. Researchers obtained that the lattice energy of MXenes was negative by first-principles analysis, which indicated that MXenes could exist stably at room temperature and pressure. Comparing the stability of $\mathrm{Ti}_{\mathrm{n}+1} \mathrm{C}_{\mathrm{n}}$ with that of $\mathrm{Ti}_{\mathrm{n}+1} \mathrm{~N}_{\mathrm{n}}$, it was found that the stability of $\mathrm{Ti}_{\mathrm{n}+1} \mathrm{C}_{\mathrm{n}}$ increased with the increase of $n$ value. And the formation energy of MXenes decreases with the increase of $n$ value. Compared with $\mathrm{Ti}_{\mathrm{n}+1} \mathrm{~N}_{\mathrm{n}}$, the formation energy of $\mathrm{Ti}_{\mathrm{n}+1} \mathrm{C}_{\mathrm{n}}$ is lower, which indicates that the stability of carbon-containing MXenes are better than that of nitrogen-containing MXenes. The results of thermogravimetric analysis and differential scanning calorimetry showed that $\mathrm{Ti}_{3} \mathrm{C}_{2} \mathrm{~T}_{\mathrm{X}}$ remained stable at $800^{\circ} \mathrm{C}$ under argon protection.

\subsection{Mechanical properties of MXenes}

Compared with typical transition metal carbides, the elastic modulus of monolayer $\mathrm{Ti}_{3} \mathrm{C}_{2}(\mathrm{OH})_{2}$ is about $300 \mathrm{GPa}$ by theoretical calculation results, the two are similar, smaller than the elastic modulus of graphene, but its elastic modulus is higher than that of most oxides and layered clays. MXenes obtained by etching with lithium salts and hydrochloric acid solutions can exhibit the properties of conductive clays. The MXenes films prepared by mixing clay groups with water and rolling have good properties. This kind of conductive film has good flexibility, foldable bending, and certain strength, and can maintain the integrity of the structure after repeated treatment.

\subsection{Other characteristics}

MXenes are obtained by etching in MAX phase, which also inherits many excellent properties of MAX phase. Theoretically, the overlayed MXenes have a large surface area, and their adsorption and hydrogen storage properties are much better than those of the original phase. Strong adsorption and hydrogen storage properties can have great application potential in environmental pollution. Other features of MXenes can be seen in Figure 2.

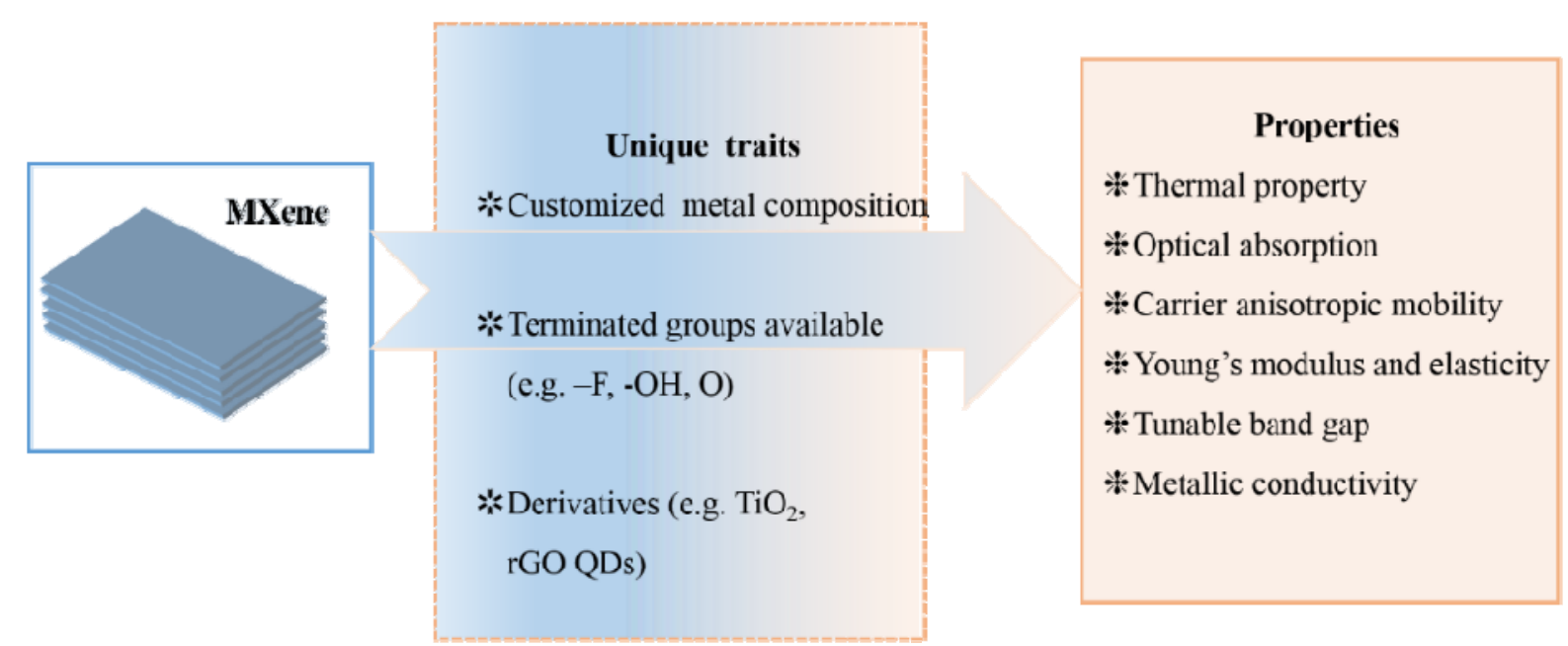

Fig. 2 - Other features of MXene. 


\section{PREPARATION OF MXENES MATERIALS}

\section{General preparation method of fluorine-containing etching}

According to Naguib's study, the synthesis process of thin-layer MXenes is mainly divided into two steps what we can see from Figure $3^{44}$ and Figure $4:{ }^{45}$ the first step is to put the MAX phase powder in a certain concentration of HF solution and stir for a certain time, break the M-A bond, etch the A layer, thus forming a multilayer MXenes. The second step is to use polar organic molecule intercalators (e.g. dimethyl sulfoxide, isopropylamine, etc.) to stretch the interlayer of the multilayer MXenes so that the interlayer spacing becomes larger. The multilayer MXenes are made into monolayer or thin layer MXenes by liquidphase ultrasonic peeling method, which can effectively improve the specific surface area and effective active area of MXenes materials. The preparation process is shown in the Figure.

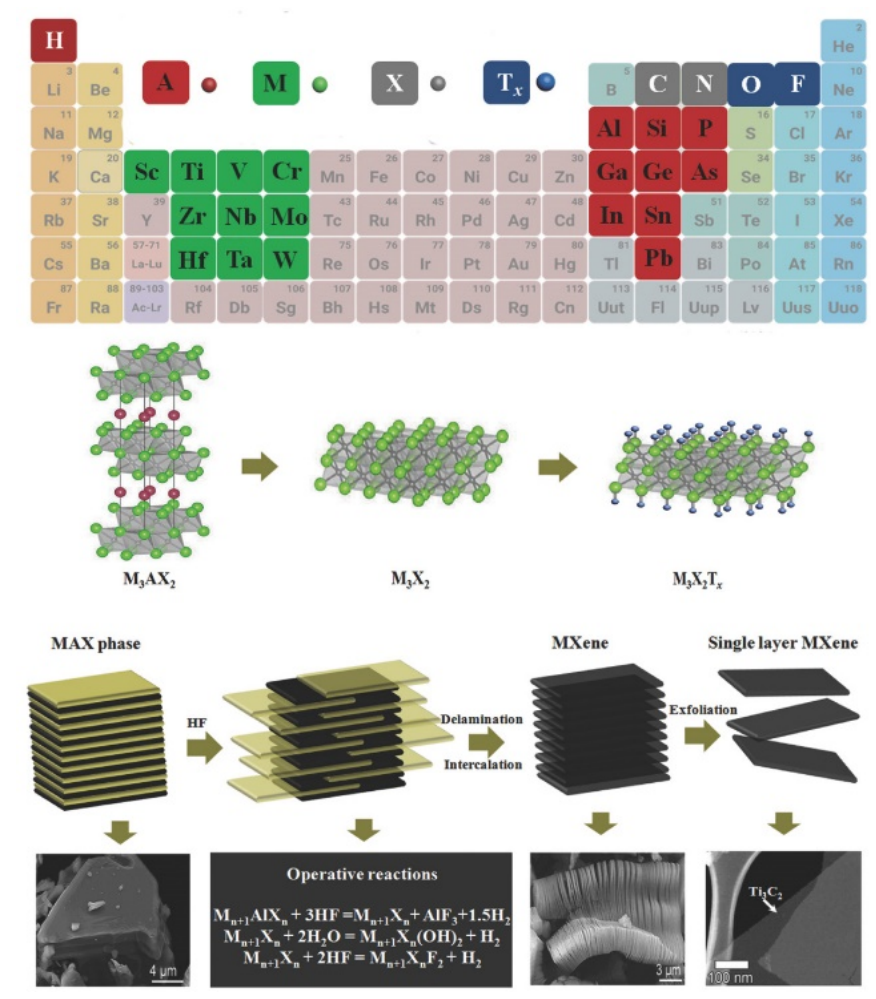

Fig. 3 - Configuration diagram of $\mathrm{M}_{3} \mathrm{AX}_{2}, \mathrm{M}_{3} \mathrm{X}_{2}$ and $\mathrm{M}_{3} \mathrm{X}_{2} \mathrm{~T}_{\mathrm{x}}$ and flow chart of mxene prepared by hydrofluoric acid etching ${ }^{44}$.

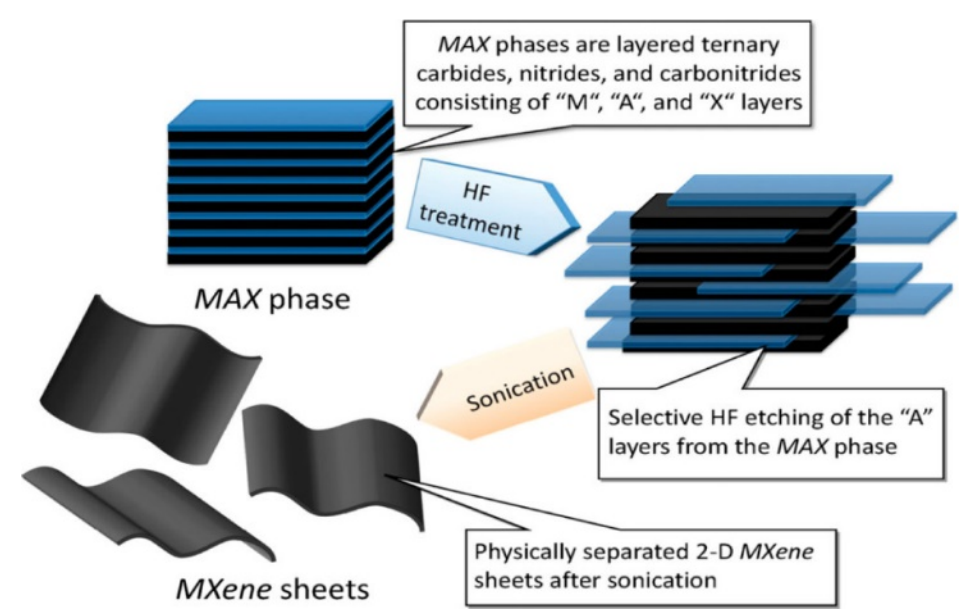

Fig. 4 - (a) Schematic diagram of MXene preparation; (b) SEM diagram of MXene; (c) TEM diagram of MXene; (d) TEM diagram of MXene ${ }^{45}$. 


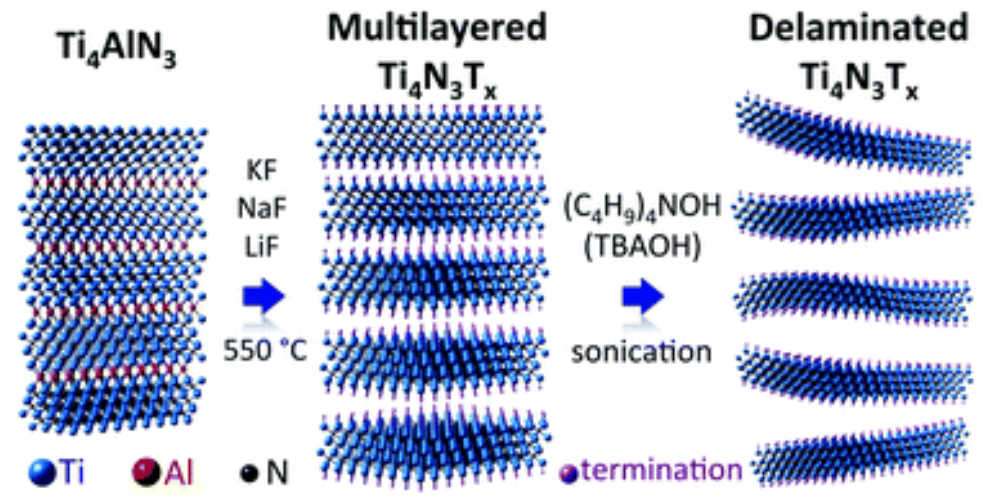

Fig. 5 - Flow chart of preparing $2 \mathrm{D} \mathrm{Ti}_{4} \mathrm{~N}_{3}$ material $^{46}$.

Naguib et al. continued their research and found that in addition to HF, a mixture of strong acids and fluorine-containing salts could also be used to etch the MAX phase to produce MXenes materials. $\mathrm{HCl}$ and LiF can react, generate HF in situ and selectively etch A layer atoms, indicating that the presence of protons and fluoride ions is necessary for etching MAX phase to form MXenes materials. Metal halides $\left(\right.$ e.g., $\left.\mathrm{Li}^{\dagger}\right)$ can enter the interlayer of MXenes materials to increase the interlayer spacing and weaken the interaction between them. The peeling process requires no addition of other substances and is directly ultrasonic.

The above two methods are very effective in treating common MAX phases and preparing them into MXenes materials, but they can not achieve good etching effect for some special MAX phases, such as MAX phases composed of different elements, transition metal nitrides, etc. Because of the differences in bonding between elements and their own stability in each compound, certain special MAX phases need to be treated in different ways. For example, Urbankowski et al ${ }^{46}$ proposed a new method to prepare two-dimensional $\mathrm{Ti}_{4} \mathrm{~N}_{3}$ materials by melting and heat treatment of $\mathrm{Ti}_{4} \mathrm{AlN}_{3}$ with fluorine-containing salts. As shown in Figure 5, a fluorine salt mixture composed of $\mathrm{KF}, \mathrm{LiF}$ and $\mathrm{NaF}$ was used, and then mixed with $\mathrm{Ti}_{4} \mathrm{AlN}_{3}$ to remove $\mathrm{Al}$ from $\mathrm{Ti}_{4} \mathrm{AlN}_{3}$ precursor under an argon atmosphere of $550^{\circ} \mathrm{C}$ to obtain nanopowders.

\section{Other methods}

Nowadays, the commonly used methods to prepare monolayers are mainly using hydrofluoric acid or fluorine-containing materials for etching and ultrasonic peeling. However, fluorine-based etchants are highly corrosive, toxic and dangerous to operate, which limits the practical application of this material. Therefore, it is of great significance to find a simple, safe and operable fluorine-free method to prepare monolayer MXenes materials. As shown in Figure 6, Gogotsi et $a l^{47}$ prepared high-quality twodimensional ultrathin $\alpha-\mathrm{Mo}_{2} \mathrm{C}$ crystals by chemical vapor deposition, which were only a few nanometers thick and over $100 \mathrm{um}$ in size, and were quite stable at room temperature. In addition, this method has general applicability, and $\mathrm{WC}$ and $\mathrm{TaC}$ crystals can be prepared by the same method.

Shein et $\mathrm{al}^{48}$ proposed an efficient, fluorinefree electrochemical method to strip $\mathrm{Ti}_{3} \mathrm{C}_{2}$. As the Figure 7 shows, chloride ions can rapidly etch $\mathrm{Al}$ to break the Ti-Al bond in this system. $\mathrm{NH}_{4} \mathrm{OH}$ plays a crucial role for the subsequent intercalation, which can promote the etching of the surface layer. The anode $\left(\mathrm{Ti}_{3} \mathrm{AlC}_{3}\right)$ can be completely etched in a short time $(5 \mathrm{~h})$ at room temperature. The yield of peeled monolayer or bilayer is over $90 \%$, and the average size is over 2 um, which is larger than the size etched with traditional HF. The resulting peeled $\mathrm{Ti}_{3} \mathrm{CT}_{\mathrm{x}}$ nanosheet terminals do not contain $\mathrm{F}$ due to the absence of $\mathrm{F}$ etching.

Li et al. ${ }^{49}$ synthesized MXenes materials by molten salt method in 2019, this method is a general method for synthesizing a series of MXenes based on $\mathrm{Zn}$ MAX phase and $\mathrm{Cl}$ sealing end through the replacement reaction between MAX phase and transition metal halides. This method is a top-down method that allows a later transition element atom ( $\mathrm{Zn}$ in the current example) to occupy the A position in the largest phase structure previously existing. Novel MAX phase $\mathrm{Ti}_{3} \mathrm{ZnC}_{2}, \mathrm{Ti}_{2} \mathrm{ZnC}, \mathrm{Ti}_{2} \mathrm{ZnN}$ and $\mathrm{V}_{2} \mathrm{ZnC}$ were synthesized using this displacement reaction between the $\mathrm{Zn}$ element of molten $\mathrm{ZnCl}_{2}$ and $\mathrm{Al}$ element in MAX phase precursors $\left(\mathrm{Ti}_{3} \mathrm{AlC}_{2}\right.$, $\mathrm{Ti}_{2} \mathrm{AlC}, \mathrm{Ti}_{2} \mathrm{AlN}$ and $\mathrm{V}_{2} \mathrm{AlC}$ ). When an excessive amount of $\mathrm{ZnCl}_{2}$ is used, $\mathrm{Ti}_{3} \mathrm{ZnC}_{2}$ and $\mathrm{Ti}_{2} \mathrm{ZnC}$ will subsequently are produced due to the strong Lewis acidity of molten $\mathrm{ZnCl}_{2}$, thereby generating $\mathrm{Cl}$ terminated MXenes (such as $\mathrm{Ti}_{3} \mathrm{C}_{2} \mathrm{Cl}_{2}$ and 
$\mathrm{Ti}_{2} \mathrm{CCl}_{2}$ ). This is the first time that only $\mathrm{Cl}$ terminated MXenes have been obtained. The etching effect of molten salt due to strong Lewis acidity provides a green and feasible way to prepare MXenes without HF chemical method.

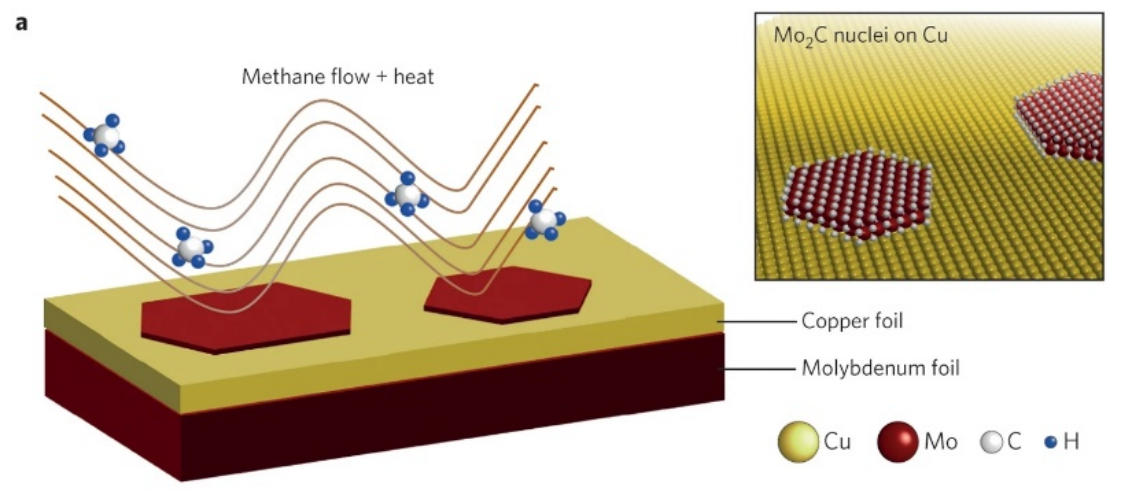

b
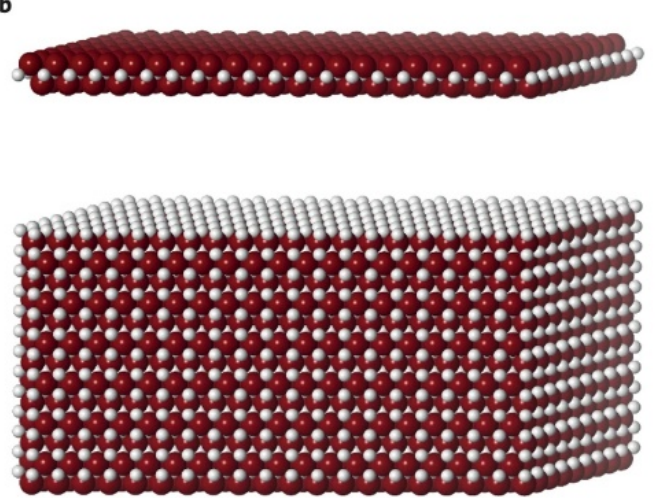

c
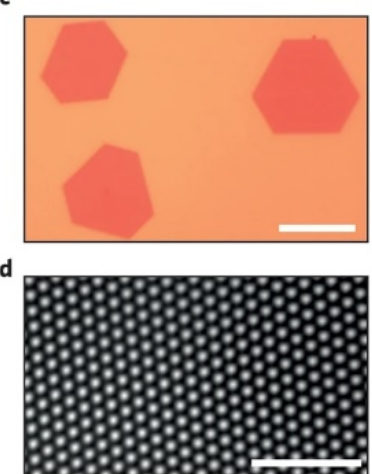

Fig. 6 - 2D carbide crystals produced by chemical vapor deposition. (a) Schematic diagram of synthesis process. Molybdenum dissolves in molten copper above $1085^{\circ} \mathrm{C}$. when Mo atom reacts with carbon atom produced by $\mathrm{CH}_{4}$ decomposition on the molten surface, a perfect $\alpha$ $\mathrm{Mo}_{2} \mathrm{C}$ crystal can be grown (as shown in the figure). (b) Single layer $\mathrm{Mo}_{2} \mathrm{C}$ (top) and 3 nanometer thick $\alpha-\mathrm{Mo}_{2} \mathrm{C}$ crystal (bottom). (c) Optical micrographs of tungsten carbide crystals grown on copper / tungsten foil double layers by chemical vapor deposition. Scale, $10 \mu \mathrm{M}$. (d) High resolution transmission electron micrograph shows the ordered crystal structure of WC crystal. Scale, $2 \mathrm{~nm}^{47}$

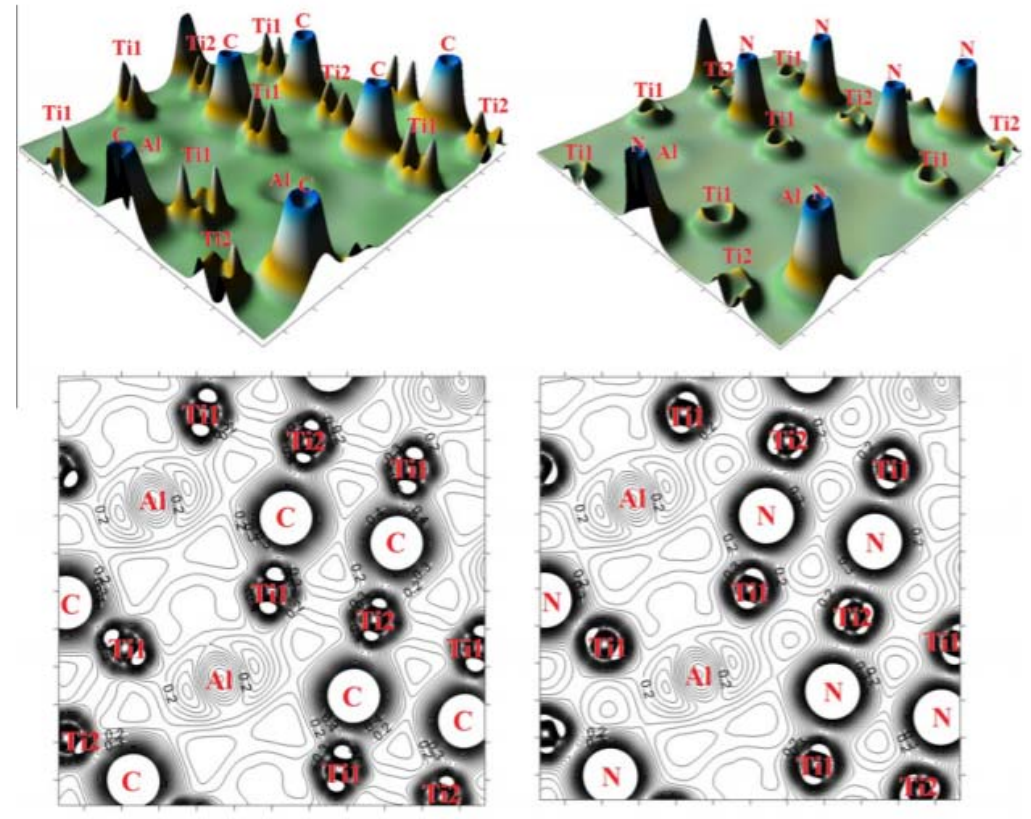

Fig. 7 - Calculated valence electron densities of the largest phases $\mathrm{Ti}_{2} \mathrm{AlC}$ and $\mathrm{Ti}_{2} \mathrm{AlN}$. The non-equivalent Ti atoms (Ti1 and Ti2) are marked. ${ }^{48}$ 


\section{APPLICATION OF MXENES MATERIALS IN PHOTOCATALYSIS}

\section{Photocatalytic Hydrogen Production by MXenes Materials}

MXenes are used as cocatalysts to attract photogenerated electrons, which provides a new idea for preparing a catalyst that can efficiently convert sunlight. Photogenerated electrons are transferred to MXenes cocatalyst to participate in the reduction reaction. In this case, MXene not only effectively inhibits the recombination of electrons and holes, but also provides active sites for redox reactions.Similarly, the photocatalyst containing MXenes has excellent performance, which is expected to replace precious metals and reduce the cost. It provides a new way for the development and application of efficient photocatalysts.

Zhang et al. ${ }^{50}$ prepared $\mathrm{MoS}_{2} / \mathrm{Ti}_{3} \mathrm{C}_{2}$ catalysts with unique spherical/flake structure by hydrothermal method. The maximum hydrogen production of $30 \% \quad \mathrm{Ti}_{3} \mathrm{C}_{2}$ loaded $\mathrm{MoS}_{2} / \mathrm{Ti}_{3} \mathrm{C}_{2}$ heterostructure was $6144.7 \mathrm{mmol} \mathrm{g}^{-1} \mathrm{~h}^{-1}$, which was 2.3 times that of pure $\mathrm{MoS}_{2}$. The heterostructure maintained high catalytic activity for four cycles. The heterostructure can effectively reduce the recombination of photogenerated electrons and holes by using its special conduction and valence band positions, and provide more activation reaction sites, thus greatly improving the photocatalytic performance. a

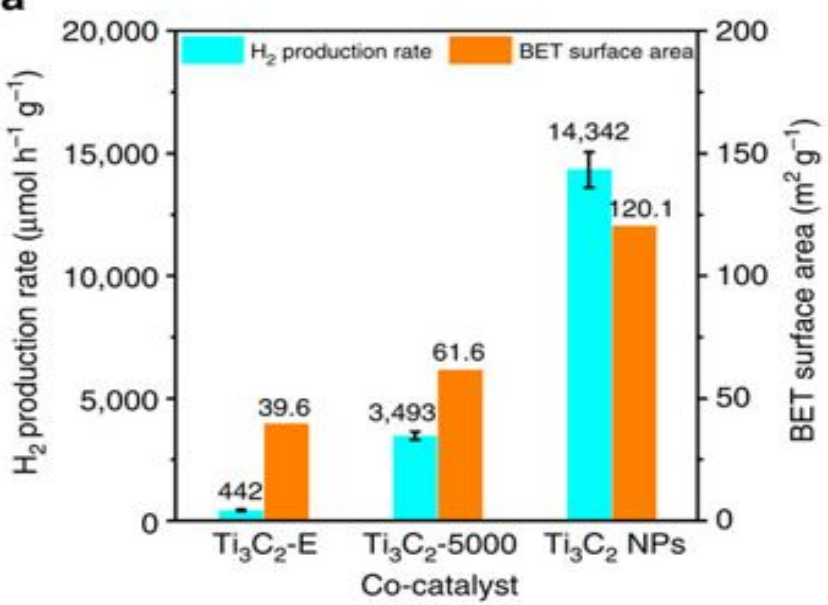

C

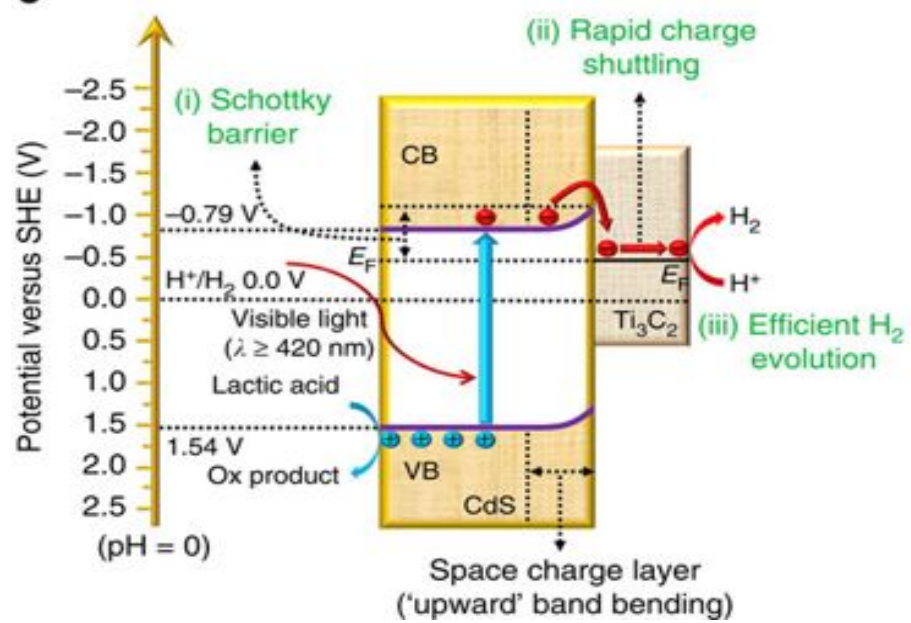

b

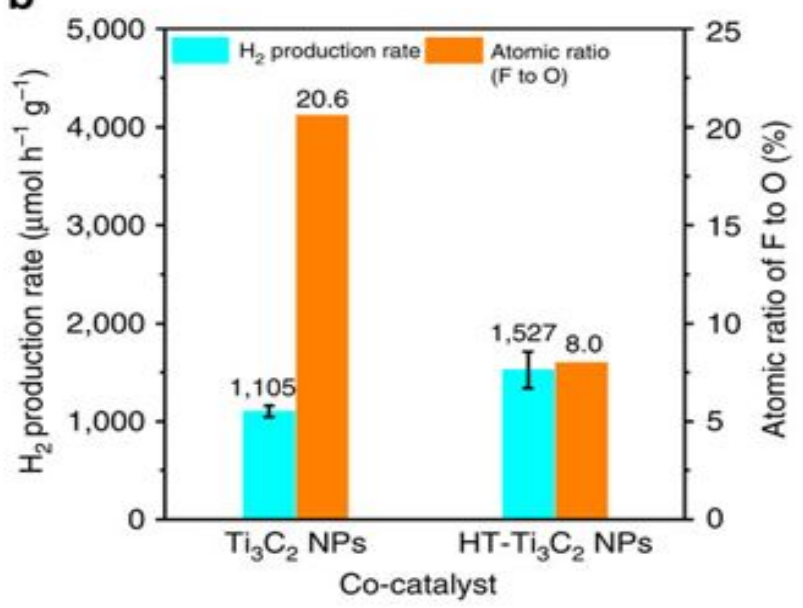

d

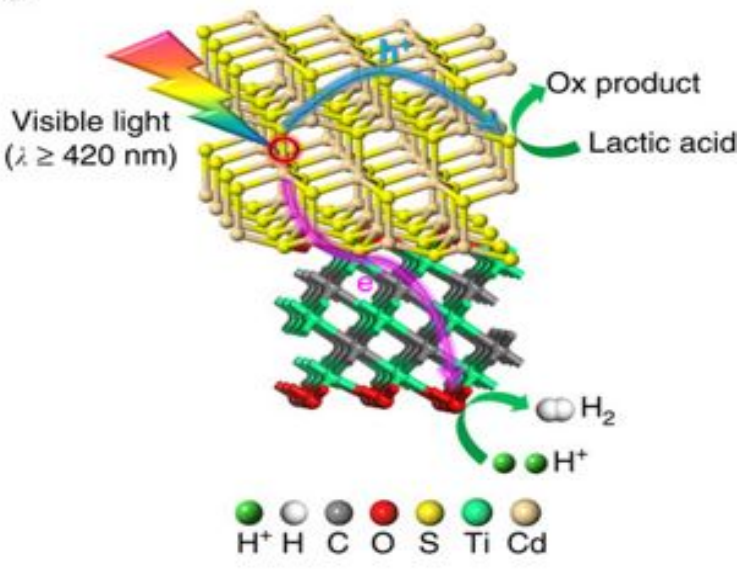

Fig. 8 - (a) effect of surface area of cocatalyst on photocatalytic activity. The error line is defined as S.D.

(b) The effect of the ratio of $\mathrm{F}$ to $\mathrm{O}$ atoms on the photocatalytic activity of cocatalyst. The error line is defined as S.D. (c) Charge separation and transfer in $\mathrm{CdS} / \mathrm{Ti}_{3} \mathrm{C}_{2}$ system under visible light irradiation. Red and blue spheres represent photoelectrons and holes, respectively. (d) The proposed mechanism of photocatalytic $\mathrm{H}_{2}$ production in $\mathrm{CdS} / \mathrm{Ti}_{3} \mathrm{C}_{2}$ system under visible light irradiation. The green ball indicates $\mathrm{H}^{+}$. White, gray, red, yellow, cyan and gold spheres represent $\mathrm{H}, \mathrm{C}, \mathrm{O}, \mathrm{S}, \mathrm{Ti}$ and $\mathrm{CD}$ atoms respectively. ${ }^{51}$ 
CdS has good semiconductor performance and visible light activity, and is considered to be a promising photocatalytic material, which is favored in the photolysis of water for hydrogen production. However, CdS is prone to photocorrosion and photogenerated electron-hole pairs are easy to recombine, resulting in low photocatalytic efficiency. To solve this problem, MXene cocatalyst was added to improve the efficiency of hydrogen production. In 2017, Ran et al. ${ }^{51}$ reported the research of incorporating MXene catalyst- $\mathrm{Ti}_{3} \mathrm{C}_{2}$ into $\mathrm{CdS}$ light absorber, and the experimental results showed that it could promote the efficiency of photocatalytic hydrogen production. What we can see from Figure 8, coupling $\mathrm{Ti}_{3} \mathrm{C}_{2}$ with $\mathrm{CdS}$ results in high-power photocatalysts, at the same time, it plays a certain role in light absorption, charge separation and interfacial catalytic reaction. These special structures enhance photoelectron transition, prolong photocatalytic lifetime, improve photocatalytic performance, and significantly increase hydrogen production. Recently, Xiao et $a l .{ }^{52}$ prepared one-dimensional (1D) CdS nanorods / 2D MXene nanosheet heterojunctions with good photocatalytic performance by in situ assembly on ultrathin $\mathrm{Ti}_{3} \mathrm{C}_{2}$ MXene nanosheets via solvothermal method. This heterostructure accelerates charge separation and provides a lower Schottky barrier to produce hydrogen from solar-driven water splitting.

Cheng et al. ${ }^{53}$ prepared $\mathrm{CdLa}_{2} \mathrm{~S}_{4} / \mathrm{Ti}_{3} \mathrm{C}_{2}$ nanocomposites by growing $\mathrm{CdLa}_{2} \mathrm{~S}_{4}$ nanoparticles in situ on the $\mathrm{Ti}_{3} \mathrm{C}_{2}$ nanosheet surface. The high stability nanocomposites have good photocatalytic activity for visible light and high $\mathrm{H}_{2}$ efficiency for water decomposition. When $\mathrm{Ti}_{3} \mathrm{C}_{2}$ content was 1.0 $\mathrm{wt} \%$, the maximum hydrogen production capacity of $\mathrm{CdLa}_{2} \mathrm{~S}_{4} / \mathrm{Ti}_{3} \mathrm{C}_{2}$ nanocomposite was 11182.4 $\mathrm{mol} \cdot \mathrm{g}^{-1} \cdot \mathrm{h}^{-1}$, which was 13.4 times higher than the original pure $\mathrm{CdLa}_{2} \mathrm{~S}_{4}$ and even exceeded the $\mathrm{CdLa}_{2} \mathrm{~S}_{4}$ supported by Pt. This contributes to the separation of photogenerated electron-hole pairs.

$\mathrm{Li}$ et al. ${ }^{54}$ constructed $\mathrm{g}-\mathrm{C}_{3} \mathrm{~N}_{4} / \mathrm{Ti}_{3} \mathrm{C}_{2}$-MXene photocatalyst by electrostatic self-assembly of PEIdoped $\mathrm{Ti}_{3} \mathrm{C}_{2}$ and $\mathrm{g}-\mathrm{C}_{3} \mathrm{~N}$ nanometer tablets. The positively charged $\mathrm{PEI}$ polymer interacts with negatively charged $\mathrm{Ti}_{3} \mathrm{C}_{2}$ and converts the surface to a negative charge in Figure 9. The results show that the electrostatic effect fixes $\mathrm{Ti}_{3} \mathrm{C}_{2}$ on the $\mathrm{Ti}_{3} \mathrm{C}_{2}$ and $\mathrm{g}_{-} \mathrm{C}_{3} \mathrm{~N}_{4}$ nanometer sheet, making the two components in close contact. The prepared $\mathrm{g}-\mathrm{C}_{3} \mathrm{~N}_{4}$ $/ \mathrm{Ti}_{3} \mathrm{C}_{2}$ extended carrier life, enhanced electronhole separation, and produced hydrogen several times as much as $\mathrm{Pt} / \mathrm{g}-\mathrm{C}_{3} \mathrm{~N}_{4}$. The excellent performance of $\mathrm{g}-\mathrm{C}_{3} \mathrm{~N}_{4} / \mathrm{Ti}_{3} \mathrm{C}_{2}$ photocatalyst can be realized by effective interfacial electron transfer and quantization of $\mathrm{Ti}_{3} \mathrm{C}_{2}$. Due to the excellent performance of MXenes, charge separation, transmission and high efficiency of redox reaction greatly improve the efficiency of hydrogen production. This study also provides a new way for the development of $\mathrm{Ti}_{3} \mathrm{C}_{2}$-Mxenes based photocatalytic hydrogen production materials.
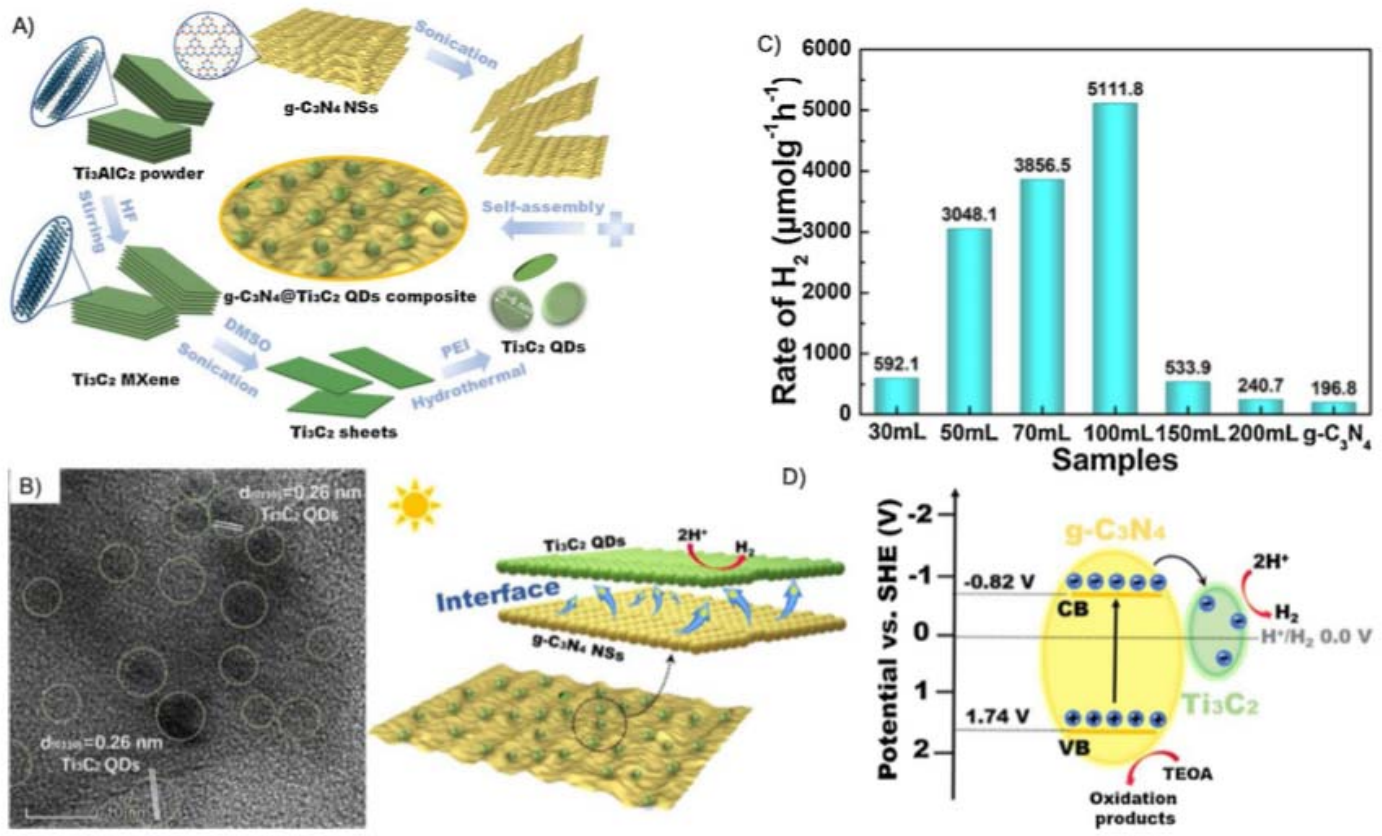

Fig. 9 - (A) schematic diagram of production path; (B) HR-TEM; (C) Photocatalytic $\mathrm{H}_{2}$ rate of photocatalysts; (D) Schematic Photocatalytic Mechanism of g- $\mathrm{C}_{3} \mathrm{~N}_{4} @ \mathrm{Ti}_{3} \mathrm{C}_{2}$ QD Composites. ${ }^{54}$ 

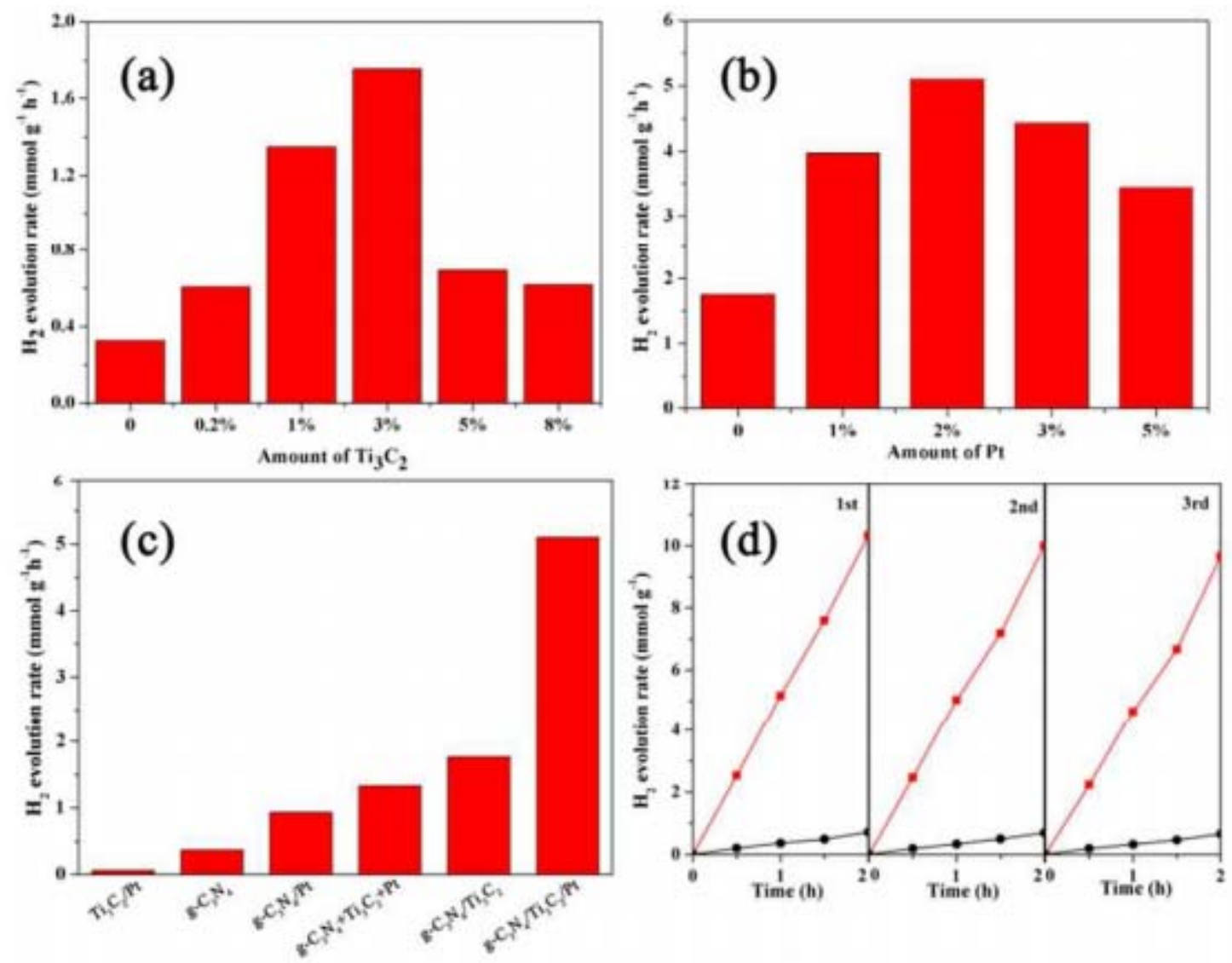

Fig. 10 - (a) $\mathrm{H}_{2}$ evolution over g- $\mathrm{C}_{3} \mathrm{~N}_{4} / \mathrm{Ti}_{3} \mathrm{C}_{2}$ with different $\mathrm{Ti}_{3} \mathrm{C}_{2}$ content; (b) $\mathrm{H}_{2}$ evolution over g- $\mathrm{C}_{3} \mathrm{~N}_{4} / \mathrm{Ti}_{3} \mathrm{C}_{2} / \mathrm{Pt}$ with different Pt content $\left(\mathrm{Ti}_{3} \mathrm{C}_{2}\right.$ content $3 \%$ ); (c) Photoactivities of different photocatalysts for $\mathrm{H}_{2}$ production; (d) Stability study of $\mathrm{H}_{2}$ evolution of g- $\mathrm{C}_{3} \mathrm{~N}_{4} / 3 \% \mathrm{Ti}_{3} \mathrm{C}_{2} / 2 \%$ Pt under simulated solar light. ${ }^{55}$

An et $a l .^{55}$ studied the use of platinum nanoclusters and $\mathrm{Ti}_{3} \mathrm{C}_{2}$-Mxene nanoparticles as cocatalysts, providing the possibility to improve the photoactivity of $\mathrm{g}_{-} \mathrm{C}_{3} \mathrm{~N}_{4}$ producing hydrogen. Thanks to the synergistic effect between $\mathrm{Ti}_{3} \mathrm{C}_{2}$ and $\mathrm{Pt}$, which improves the conductivity and also increases the reaction sites of photoreduction reaction, the photocatalyst modified with $\mathrm{Ti}_{3} \mathrm{C}_{2}$ and $\mathrm{Pt}$ has better photocatalytic hydrogen production performance. Compared with $\mathrm{g}-\mathrm{C}_{3} \mathrm{~N}_{4} / \mathrm{Ti}_{3} \mathrm{C}_{2}$ and g$\mathrm{C}_{3} \mathrm{~N}_{4} / \mathrm{Pt}$, the photoactivity was increased by 3 -fold and 5-fold, indicating that $\mathrm{Ti}_{3} \mathrm{C}_{2} \mathrm{MXene}$ has great potential to construct high-performance photocatalysts. It is shown in Figure 10 that there are potential synergistic effects among different cocatalysts to make heterostructure photocatalysts have better photocatalytic activity.

Jia et al..$^{56}$ obtained high carbon-doped and high carbon-doped $\mathrm{TiO}_{2}$ nanorods with $\mathrm{MXene} \mathrm{Ti}_{3} \mathrm{C}_{2}$, showing better photoactivity than commercial P25 for hydrogen production. $\mathrm{Cu}^{57}$ et al. constructed catalysts with layered Pt-MXene-single-walled carbon nanotubes (SWCNTs) heterostructures. In the heterostructure, the highly active nano / atomic metal $\mathrm{Pt}$ was fixed on $\mathrm{Ti}_{3} \mathrm{C}_{2} \mathrm{~T}_{\mathrm{x}}$-MXene sheet
(MXene@Pt) and connected to the SWCNT network. Hierarchical heterostructures were constructed by filtering mixed colloidal suspensions containing MXene@Pt and SWCNT. Using MXene's unique hydrophilicity and reductivity, MXene@Pt can spontaneously reduce platinum ions to metallic platinum to prepare colloidal suspension without adding reductant or post-treatment. The thin-film layered HER catalyst prepared shows high stability during 800 hours of operation, and is an efficient and stable catalyst for hydrogen production.

\section{Reduction of Carbon Dioxide by MXenes Materials}

MXene has typical layered structure, excellent electrical conductivity, hydrophilicity and electronegativity, and is an excellent platform for catalytic reduction of $\mathrm{CO}_{2}$. DFT calculation shows that Oterminal MXene (such as $\mathrm{Ti}_{3} \mathrm{CO}_{2}$ and $\mathrm{W}_{2} \mathrm{CO}_{2}$ ) performs well in catalytic conversion to $\mathrm{CO}_{2}$. The following sections describe the latest progress of MXenes as photocatalysts for carbon dioxide reduction. 


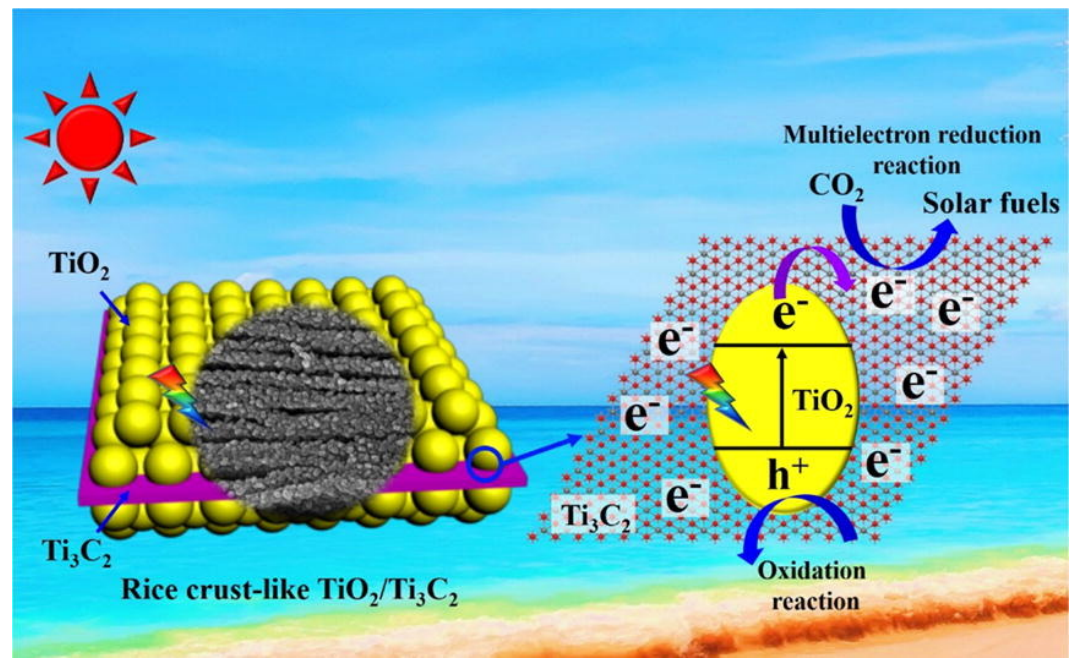

Fig. 11 - Reduction of $\mathrm{CO}_{2}$ by photocatalyst $\mathrm{TiO}_{2} / \mathrm{Ti}_{3} \mathrm{C}_{2}$ sample. ${ }^{58}$

\subsection{Titanium-based MXenes}

As a photocatalyst, Ti-MXenes $\left(\mathrm{Ti}_{3} \mathrm{C}_{2}\right)$ is a promising photocatalytic scheme for $\mathrm{CO}_{2}$ reduction due to its unique structure and advantages. Therefore, when $\mathrm{Ti}_{3} \mathrm{C}_{2}$ is coupled with a semiconductor photocatalyst, it is conducive to electron hole separation due to its high electron conductivity and low Fermi energy level. In addition, the calculated results show that the oxygen vacancies containing $\mathrm{Ti}_{3} \mathrm{C}_{2} \mathrm{O}_{2}$ MXenes have high selectivity, which is conducive to the photocatalytic reduction of $\mathrm{CO}_{2}$. $\quad \mathrm{TiO}_{2} / \mathrm{Ti}_{3} \mathrm{C}_{2}$ composites have been prepared by a feasible calcination method. The in-situ growth of $\mathrm{TiO}_{2}$ obtained by converting $\mathrm{Ti}_{3} \mathrm{C}_{2}$ during the calcination step forms a close contact between the thin shell structure of $\mathrm{Ti}_{3} \mathrm{C}_{2}$ and $\mathrm{TiO}_{2}$ with a large surface area. Therefore, in this case, $\mathrm{Ti}_{3} \mathrm{C}_{2}$ MXenes are used as cocatalysts to enhance charge separation and provide suitable active sites for reduction reactions. What we can see from Figure 11, reduction of $\mathrm{CO}_{2}$ by the photocatalyst $\mathrm{TiO}_{2} / \mathrm{Ti}_{3} \mathrm{C}_{2}$ sample produced various organic compounds, among which $\mathrm{CH}_{4}$ was the main product, indicating that the $\mathrm{TiO}_{2} / \mathrm{Ti}_{3} \mathrm{C}_{2}$ composite has excellent activity and selectivity. ${ }^{58}$

In another study, ${ }^{59}$ it has been reported that an attempt has been made to fabricate an efficient material using the structure of a two-dimensional 2D/2D $\mathrm{Ti}_{3} \mathrm{C}_{2} / \mathrm{Bi}_{2} \mathrm{WO}_{6}$ heterojunction, which has strong solar absorption capacity, strong electron separation capacity and reduction capacity and can be converted to $\mathrm{CO}_{2}$. The in-situ growth of $\mathrm{Bi}_{2} \mathrm{WO}_{6}$ on $\mathrm{Ti}_{3} \mathrm{C}_{2}$ by hydrothermal treatment results in a firm interface contact between the two materials, and the main reason for the formation of
$\mathrm{Bi}_{2} \mathrm{WO}_{6}$ on $\mathrm{Ti}_{3} \mathrm{C}_{2}$ surface is the electrostatic attraction between $\mathrm{Bi}^{3+}$ positive ion and $\mathrm{Ti}_{3} \mathrm{C}_{2}$ negative ion surface. The prepared $\mathrm{Ti}_{3} \mathrm{C}_{2} / \mathrm{Bi}_{2} \mathrm{WO}_{6}$ has unique properties and is very valuable for photocatalytic $\mathrm{CO}_{2}$ reduction. First of all, the composites prepared under the optimal conditions have strong $\mathrm{CO}_{2}$ adsorption capacity because of their large specific surface area and strong $\mathrm{CO}_{2}$ affinity. When the concentration of $\mathrm{CO}_{2}$ dioxide on the catalyst surface is high, this can promote the kinetic advantage of the reaction. In addition, close contact enables effective interfacial charge transfer channels and prolongs the lifetime of charge carriers. It is speculated that Ti-based MXenes have unique 2D structure, effective electronic attraction ability and suitable surface properties, which are the main reasons for promoting interfacial electron transfer and $\mathrm{CO}_{2}$ reduction.

As a novel method, using the unique properties of $\mathrm{Ti}_{3} \mathrm{C}_{2}$ molecules, $\mathrm{Ti}_{3} \mathrm{C}_{2}$ quantum dots (QDs) obtained from two-dimensional materials can be used in $\mathrm{CO}_{2}$ applications. ${ }^{60}$ In this paper, $\mathrm{Ti}_{3} \mathrm{C}_{2}$ QDs / $\mathrm{Cu}_{2} \mathrm{O}$ nanowires / $\mathrm{Cu}$ (NWs) heterostructure is reported. The preparation of catalyst includes three steps: firstly, $\mathrm{Ti}_{3} \mathrm{C}_{2}$ QDs doped with polyethyleneimine is synthesized, then $\mathrm{Cu}_{2} \mathrm{O}$ NWs / $\mathrm{Cu}$ is modified with sodium polystyrene sulfonate (PSS), and finally the required materials are synthesized by self-assembly. It is worth noting that the electrostatic force between PEI- $\mathrm{Ti}_{3} \mathrm{C}_{2}$ with positive charge and $\mathrm{PSS}-\mathrm{Cu}_{2} \mathrm{O}$ NWS / Cu with negative charge is the key premise to promote the uniform existence of $\mathrm{Ti}_{3} \mathrm{C}_{2}$ QDs on $\mathrm{Cu}_{2} \mathrm{O}$ NWS / $\mathrm{Cu}$ and start the successful preparation method. Compared with $\mathrm{Ti}_{3} \mathrm{C}_{2}$ sheet $/ \mathrm{Cu}_{2} \mathrm{O}$, NWs / Cu and $\mathrm{Ti}_{3} \mathrm{C}_{2}$ QDs $/ \mathrm{Cu}_{2} \mathrm{O}$, the enhanced light absorption and smaller band gap of NWs / $\mathrm{Cu}$ heterostructure 
are attributed to the presence of $\mathrm{Ti}_{3} \mathrm{C}_{2}$ QDs, respectively. Therefore, it can be demonstrated that $\mathrm{Ti}_{3} \mathrm{C}_{2}$ QDs are a co-catalyst that provides an active center for the carbon dioxide reduction reaction because the electrons produced can be absorbed. The photocatalytic performance showed a high yield of $\mathrm{CO}_{2}$ reduction to methanol $\left(\mathrm{CH}_{3} \mathrm{OH}\right)$.

The aforementioned examples demonstrate that Ti-MXenes can be used for highly selective photocatalytic reduction of $\mathrm{CO}_{2}$, which both theoretically and computationally predict a bright future for these materials. However, the coupling of $\mathrm{Ti}_{3} \mathrm{C}_{2}$ cocatalyst with various semiconductor photocatalysts requires a lot of research. In addition, the simulation of this structure will contribute to a deeper understanding of the way $\mathrm{Ti}_{3} \mathrm{C}_{2}$ specifically adsorbs, activates and charge transfer mechanisms.

\subsection{Other MXenes}

In 2017, Li et al. ${ }^{61}$ revealed the key discovery of $\mathrm{Cr}_{3} \mathrm{C}_{2}$ and $\mathrm{Mo}_{3} \mathrm{C}_{2}$ MXenes that selectively converted $\mathrm{CO}_{2}$ to $\mathrm{CH}_{4}$ by using high-resolution density functional theory. The calculation results showed that compared with bare materials, MXene at the $-\mathrm{O}$ and $-\mathrm{OH}$ ends was conducive to the selective conversion of $\mathrm{CO}_{2}$ into $\mathrm{CH}_{4}$, which reduced the total free energy of the reaction.

Recently, $\mathrm{Sc}_{2} \mathrm{C}(\mathrm{OH})_{2}$ and $\mathrm{Y}_{2} \mathrm{C}(\mathrm{OH})_{2}$ MXenes containing - $\mathrm{OH}$ end groups were explored as platforms for $\mathrm{CO}_{2}$ reduction reactions by firstprinciples simulation. The negative limit potentials of $\mathrm{Sc}_{2} \mathrm{C}(\mathrm{OH})_{2}$ and $\mathrm{Y}_{2} \mathrm{C}(\mathrm{OH})_{2}$ MXenes were found to be smaller than those of $\mathrm{Cu}$. In addition, the $-\mathrm{H}$ atom in -OH plays a crucial role in forming stable substances with intermediates and reducing the overpotential. Therefore, the $\mathrm{CO}_{2}$ reduction efficiency of these MXenes was greatly improved. The calculated results prove the favorable prospects of MXenes modified by $-\mathrm{O}$ and $-\mathrm{OH}$ groups, however, the experimental studies on MXenes for photocatalytic $\mathrm{CO}_{2}$ reduction are quite limited, so there is a large amount of future work worth providing further research.

\subsection{Mechanism of MXenes as Co-Catalysts}

As most MXenes are conductors and act as cocatalysts, the mechanism of MXenes photocatalytic system is to improve the photocatalytic efficiency by accelerating charge separation and inhibiting carrier recombination. ${ }^{62-64}$ As shown in Figure 12, the photocatalyst absorbs visible light and excites photogenerated electrons to the conduction band (CB), leaving holes in the valence band (VB). MXene has a higher potential, so the excited carriers transfer to MXene at the interface and the electron recombination is suppressed and reacts on the surface of MXene. As shown in Figure 12, $\mathrm{H}_{2}{ }^{50-57,65-69}$ is generated by reducing $\mathrm{H}^{+}$or $\mathrm{CO}$ and $\mathrm{CH}_{4}{ }^{56-58}$ by reducing $\mathrm{CO}_{2}$. The process of charge transfer from photocatalyst to MXene improves the separation of electron hole pairs and inhibits the charge recombination in the photocatalyst, thus improving the photocatalytic activity.

The end group of MXene is another reason for its application in photocatalysis. For example, due to low Gibbs free energy and abundant active sites, ${ }^{64,70}$-O terminal groups show strong hydrogen production potential. ${ }^{70}$ Although end groups of MXenes are important in photocatalytic processes, the relative concentrations of various end groups cannot be accurately controlled. Using existing synthesis methods, the surface end groups of MXenes can be partially changed by changing different reaction conditions, thus affecting its photocatalytic performance.

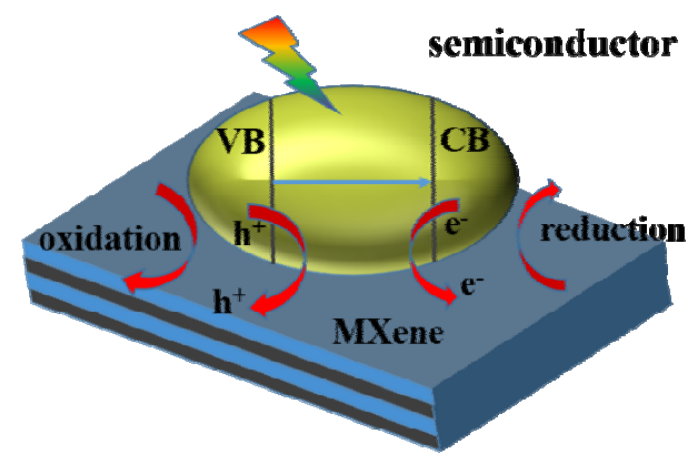

Fig. 12 - Schematic of the working mechanism of MXenes applied in photocatalysis. 


\section{CONCLUSIONS AND PROSPECTS}

According to recent research, research on MXenes have flourished since the publication of the first paper in 2011. The scientific community has already witnessed the excellent performance of MXenes as a cocatalyst in photocatalysis. However, there are still some problems in the research of MXenes:

Develop new environmentally and friendly preparation methods to realize large-scale production and preparation. Most MXenes are prepared by strong acid etching, which will cause certain harm to humans and the environment. Therefore, the development of a safe and environmental synthesis process for MXenes is very important. At present, the synthesis of MXenes is still in the laboratory research stage, and how to produce high-quality, low-cost MXene on a large scale is still a research focus.

Strengthen the research on the mechanism of action and continuously expand the new uses of MXenes. The joint efforts of the scientific community have provided a certain theoretical basis for the development of MXenes catalysts, and its application is of great significance for finding photocatalysts with high catalytic activity and high stability. In addition to exploring more MXenes materials, structural modification of existing MXenes to improve their activity is also an attractive research direction. MXenes-based photocatalysts will undoubtedly become a new research focus. More energy should be invested in this research field in the future.

Acknowledgements. This work was financially supported by the Major Projects of Natural Science Foundation of Anhui province (1808085ME129), Natural Science Research in Anhui Colleges and Universities (KJ2018ZD050), Outstanding Young Talents Support Program in Colleges and Universities (gxyqZD2018056), Key research and development projects in Anhui Province (202004a05020060).

\section{REFERENCES}

1. M. Shao, Y. Shao, J. W. Chai, Y. Qu and H. Pan, J. Mater. Chem. A, 2017, 5, 16748-16756.

2. N. K. Chaudhari, H. Jin, B. Kim, D. S. Baek, S. H. Joo and K. Lee, J. Mater. Chem. A, 2017, 5, 24564-24579.

3. B. Anasori, M. R. Luhatskaya and Y. Gogotsi, Nat. Rev. Mater, 2017, 2, 16098.

4. J. Ran, G. Gao, F. T. Li, T. Y. Ma, A. J. Du and S. Z. Qiao, Nat. Commun., 2017, 8, 13907.

5. S. W. Cao, B. J. Shen, T. Tong, J. W. Fu and J. G. Yu, $A d v$ Funct. Mater, 2018, 28, 1800136

6. X. Q. Xie, N. Zhang, Z. R. Tang, M. Anpo and Y. J. Xu. Appl. Catal. B: Envir., 2018, 237, 43-49.
7. N. R. Hemanth and B. Kandasubramanian, Chem. Eng. J, 2019, 123678.

8. H. Wang, Y. Sun, Y. Wu, W. Tu, S. Wu, X. Yuan, G. Zeng, Z. J. Xu, S. Li and J. W. Chew, Appl. Catal. B: Envir, 2019, 245, 290-301

9. T. M. Su, Z. D. Hood, M. Naguib, B. Lei and Z. Wu, Nanoscale, 2019, 11, 8138-8149.

10. F. Y. Xu, K. Meng, B. C. Zhu and H. B. Liu, Adv. Funct. Mater, 2019, 29, 1904256

11. P. Mazierski, A. Mikolajczyk, T. Grzyb, P. A. C. Nicolas and Z. Wei, Appl. Surf. Sci., 2020, 527, 146815.

12. J. N. Li, Q. C. Zhang, J. M. Liu, M. R. Yu, H. Y. Ma, J. C. Yang, S. Ye, T. R. Reina and J. Liu, J. Coll. Interface Sci., 2020, 577, 512-522

13. R. Sidaraviciute, V. Kavaliunas, L. Puodziukynas, A. Guobiene and M. Andrulevicius, Environ. Technol. Inno. 2020, 100983.

14. S. Varnagiris, M. Urbonavicius, S. Sakalauskaite, R. Daugelavicius, L. Pranevicius, M. Lelis and D. Milcius, Sci. Total Environ., 2020, 720, 137600.

15. G. Li, B. Zou, S. Feng, H. Shi and G. Zhang, Physica B, 2020, $588,412184$.

16. F. Mei, Z. Li, K. Dai, J. Zhang and C. Liang, Chinese J. Catal., 2020, 41, 41-49.

17. M. Liu, S. Wageh, A. A. Al-Ghamdi, P. Xia, B. Cheng, L. Y. Zhang and J. G. Yu, Chem. Commun., 2019, 55, $14023-14026$.

18. X. Li, C. Y. Liu, D. Y. Wu, J. Z. Li and P. W. Huo, Chinese J. Catal., 2019, 40, 928-939.

19. D. D. Ren, W. Zhang, Y. Ding, R. Shen, Z. Jiang, X. Lu and X. Li, Solar RRL, 2019, 4, 1-11.

20. T. Hu, K. Dai, J. Zhang, G. Zhu and C. Liang, Mater. Lett., 2019, 257, 126740.

21. M. Naguib, V. N. Mochalin, M. W. Barsoum and Y. Gogotsi, Adv. Mater., 2014, 26, 992-1005.

22. B. Anasori, M. R. Luhatskaya and Y. Gogotsi, Nat. Rev. Mater., 2017, 2, 16098.

23. M. Naguib, M. Kurtoglu, V. Presser, J. Lu, J. Niu, H. Min, L. Hultman, Y. Gogotsi and M. W. Barsoum, $A d v$. Mater., 2011, 23, 4248-4253.

24. X. Liu, X. Shao, F. Li and M. Zhao, Appl. Sur. Sci., 2018, $455,522-526$

25. R. Syamsai and A. N. Grace, J. Alloys Compd., 2019, $792,1230-1238$

26. J. Zhu, M. Wang, M. Lyu, Y. Jiao, A. Du, B. Luo, I. R. Gentle and L. Wang, ACS Appl. Nano Mater., 2018, 1, 6854-6863.

27. Y. Xie, M. Naguib, V. N. Mochalin, M. W. Barsoum, Y. Gogotsi, X. Yu, K. W. Nam, X. Q. Yang, A. I. Kolesnikov and P. R. C. Kent, J. Am. Chem. Soc., 2014, 136, 63856394.

28. M. Ghidiu, M. Naguib, C. Shi, O. Mashtalir, L. M. Pan, B. Zhang, J. Yang, Y. Gogotsi, S. J. L. Billinge and M. W. Barsoum, Chem. Commun., 2014, 50, 9517-9520.

29. L. Lei, S. Wang, J. Xiao, X. Bian, Y. Zhang, Micheal D. Scanlon, X. Hu, T. Yi, B. Liu and H. H. Girault, Energy Environ. Sci., 2014, 7, 387-392.

30. B. Anasori, C. Shi, E. J. Moon, Y. Xie, C. A. Voigt, P. R. C. Kent, S. J. May, S. J. L. Billinge, M. W. Barsoum and Y. Gogotsi, Nanoscale Horiz., 2016, 1, 227-234.

31. M. Khazaei, A. Ranjbar, M. Arai and S. Yunoki, Phys. Rev. $B, \mathbf{2 0 1 6}, 94,125152$.

32. J. He, G. Ding, C. Zhong, S. Li, D. Li and Z. Gang, Nanoscale,2019, 11, 356-364.

33. T. Thomas and C. R. Bowen, J. Alloys Compd., 2014, $602,72-77$. 
34. T. P. Nguyen, D. M. Nguyen, D. L. Tran, H. K. Le, D-V. N. Vo, S. S. Lam, R. S. Varma, M. Shokouhimehr, C. C. Nguyen and Q. V. Le, Mol. Catal., 2020, 486, 110850.

35. A. Lipatov, H. Lu, M. Alhabeb, B. Anasori and A. Sinitskii, Sci. Adv., 2018, 4, 1-7.

36. Y. Sun, X. Meng, Y. Dallagnese, C. DallAgnese and X. F. Wang, Nano-Micro Lett., 2019, 11, 1-22.

37. L. Clarizia, D. Russo, S. I. Di, R. Andreozzi and R. Marotta, Energies, 2017, 10, 1624-1644.

38. H. Jiang, Z. Wang, Q. Yang, L. Tan, L. Dong and M. Dong, Nano-Micro Lett., 2019, 11, 179-192.

39. L. Verger, C. Xu, V. Natu, H. M. Cheng, W. Ren and M. W. Barsoum, Curr. Opin. Solid St. M. Sci., 2019, 23, 149163.

40. M. Maliki, A. Maleki and R. S. Varma, J. Mater. Chem. A, 2019, 7, 10843-10857.

41. V. Shukla, N. K. Jena, S. R. Naqvi, W. Luo and R. Ahuja, Nano Energy, 2019, 58, 877-885.

42. Y. Hu, L. Mao, X. Guan, K. A. Tucker, H. Xie, X. S. Wu and J. W. Shi, Renew. Sust. Energ. Rev., 2020, 119, 109527.

43. A. N. Enyashin and A. L. Ivanovskii, J. Phys. Chem. C, 2013, 117, 13637-13643.

44. H. Wang, Y. Wu, X. Z. Yuan, G. M. Zeng, J. Zhou, X. Wang and J. W. Chew, Adv. Mater, 2018, 30, 1704561.

45. C. Tan, X. Cao, X. J. Wu, Q. He, J. Yang, X. Zhang, J. Chen, W. Zhao, S. Han and G. H. Nam, Chem. Rev., 2017, 117, 6225-6331.

46. P. Urbankowski, B. Anasori, T. Makaryan, D. Er and Y. Gogotsi, Nanoscale, 2016, 8, 11385-11391.

47. Y. Gogotsi, Nat. Mater, 2015, 14, 1079-1080.

48. I. R. Shein and A. L. Ivanovskii, Comput. Mater. Sci., 2012, 65, 104-114.

49. M. Li, J. Lu, K. Luo, Y. Li, K. Chang, K. Chen, J. Zhou, J. Rosen, L. Hultman and P. EklundElement, $J$. Am. Chem. Soc., 2019, 141, 4730-4737.

50. J. Zhang, C. Xing and F. Shi, Int. J. Hydrog. Energy, 2020, 45, 13559-13562.

51. Y. L. Sun, Y, Sun, X. Meng, Y. Gao, Y. DallAgnese, G. Chen, C. X. DallAgnese and X. F. Wang, Catal. Sci. Technol., 2019, 9, 310-315.

52. R. Xiao, C. X. Zhao, Z. Y. Zou, Z. P. Chen, L. Tian, H. T.
Xu, H. Tang, Q. Q. Liu, Z. X. Lin and X. F. Yang, Appl. Catal. B: Envir., 2019, 268, 118382.

53. L. Cheng, Q. Chen, J. Li and H. Liu, Appl. Catal. B: Envir., 2019,118379.

54. Y. Li, L. Ding, Y. Guo, Z. Liang and J. Tian, ACS Appl. Mater. Inter., 2019, 11, 41440-41447.

55. X. An, W. Wang, J. Wang, H. Duan and J. Shi, Phys. Chem. Chem. Phys., 2018, 20, 11405-11411.

56. G. Jia, Y. Wang, X. Cui and W. Zheng, ACS Sustain. Chem. Eng., 2018, 6, 13480-13486.

57. C. Cui, R. F. Cheng, C. Zhang, Y. H. Ma, C. Shi, B. B. Fan, H. L. Wang and X. H. Wang, Adv. Funct. Mater. 2020, 30, 1-8.

58. J. Low, L. Zhang, T. Tong, B. Shen and J. Yu, J. Catal., 2018, 361, 255-266.

59. S. W. Cao, B. J. Shen, T. Tong and J. Yu, Adv. Funct. Mater, 2018, 28, 1800136.

60. Z. Zeng, Y. Yan, C. Jie, Z. Ping and C. Peng, Adv. Funct. Mater., 2019, 29, 1806500.

61. N. Li, X. Chen, W. J. Ong, D. R. MacFarlane, X. Zhao, A. K. Cheetham and C. Sun, ACS Nano., 2017, 11, 10825-10833.

62. C. Peng, X. Yang, Y. Li, H. Yu, H. J. Wang, F. Peng, ACS Appl. Mater. Inter., 2016, 8, 6051-6060.

63. M. Ye, X. Wang, E. Liu, J. Ye, D. Wang, Chem. Sus. Chem., 2018, 11, 1606-1611.

64. J. Ran, G. Gao, F. T. Li, T. Y. Ma, A. Du and S. Z. Qiao, Nat. Commun., 2017, 8, 13907.

65. Y. Li, S. Yang, Z. Liang, Y. Xue, H. Cui and J. Tian, Mater. Chem. Front., 2019, 3, 2673.

66. T. Su, Z. D. Hood, M. Naguib, B. Lei and Z. Wu, Nanoscale, 2019, 11, 8138-8149.

67. M. Shao, Y. Shao, J. W. Chai, Y. Qu and M. Yang, $J$. Mater. Chem. A, 2017, 5, 16748-16756.

68. G. Jia, Y. Wang, X. Cui and W. Zheng, ACS Sustain. Chem. Eng., 2018, 6, 13480-13486.

69. L. N. Tie, S. Y. Yang, C. F. Yu, H. Chen and Y. M. Liu, J. Colloid Interface Sci., 2019, 545, 63-70.

70. Y. L. Sun, D. Jin, Y. Sun, X. Meng, Y. Gao, Y. DallAgnese, G. Chen and X. F. Wang, J. Mate. Chem. A, 2018, 6, 9124-9131. 
